\title{
Synthesis and Characterization of Copolymers Derived from Salicylic Acid, Acryloamide, and Furfural (SAF's) and their Study as Ion Exchange Resins for Toxic Divalent Cationic Trace Elements
}

\author{
Al-Imarah F. J. M., Khwedem, A. A. A., and Ibraheem H. K.
}

\begin{abstract}
Terpolymers (SAF's) as an ion exchange resins were synthesized by the condensation of salicylic acid and Acryloamide with furfural in mole ratios of 1:1:2 of the reacting monomers in the presence of hydrochloric acid as catalyst. The resins were characterized by FTIR for the assignment of functional groups and thermogravimetricaly analyzed by TGA in which samples were subjected to condition of continuous increase in temperature at linear rate. The thermograms showed that the resin are solids and stabes. The uptake behaviour of synthesized resins for $\mathrm{Hg}(\mathrm{II}), \mathrm{Cd}(\mathrm{II})$ and $\mathrm{Pb}$ (II) ions have been studied depending on $\mathrm{pH}$ and metal ion concentrations. The study was carried out over a $\mathrm{pH}$ range of 5-8 and in a media of certain ionic strengths by using $\mathrm{NaNO}_{3}$ as an electrolyte. Cadmium and Lead were determined by means of Atomic Absorbtion Spectrophotometry, while Mercury was determined spectrofluorometrically by adopting the method of Mudakavi (1984) which modified by Al-Imarah et al (2000). The resin polymer showed a higher selectivity for the removal of these ions in the following order $\mathrm{Pb}^{2+}>\mathrm{Hg}^{2+}>\mathrm{Cd}^{2+}$ ions. This study could be adopted for industrial waste water treatment.
\end{abstract}

Keywords - chelating resin, synthesis, distribution ratio, heavy elements, removal of pollutants.

\section{INTRODUCTION}

The term terpolymerization refers to the simultaneous polymerization of three monomers together(Syed Abuthahir, 2014). On the other hand, The polymer metal complex is a metal complex containing a polymer ligand presenting a remarkably specific structure in which central metal ions are surrounded by an enormous polymer chain (Helfferich, 1962).

Ion exchange may be defined as the reversible exchange of ions between the substrate and surrounding medium. Ion exchange technique can remove traces of ion impurities from water/process liquors and given out a product of ultra pure quality in a single efficient and techno-economically viable manner. Ion exchangers are widely used in analytical chemistry, hydrometallurgy, antibiotics, purification and

Al-Imarah F. J. M., Khwedem, A. A. A., and Ibraheem H. K, are with Dept. Chem., \& Marine Envir. Poll., Marine Science Centre, Basrah University, Basrah-Iraq. separation of radioisotopes and find large application in water treatment and pollution control (Tarase et al,. 2009, Shah et al,. 2007). Ion-exchange resins comprise one of the most important scientific developments of the $20^{\text {th }}$ century. Their applicability to water softening, environmental remediation, wastewater treatment, hydrometallurgy, chromatography, bio molecular separations, and catalysis (Shah et al., 2010). Ion exchange is a process in which mobile ions from an external solution are exchanged for ions that are electrostatically bound to the functional groups contained within a solid matrix. When the functional groups are negatively charged the exchange will involve cations and when they are positively charged they involve anions. By taking advantage of the fact that, under certain conditions, ion exchange media have a greater affinity for certain ionic species than for others, a separation of these species can be made; for example, the hydrogen form of a cation exchanger will release its hydrogen ion into solution according to the following equation (Alchin, 2004 ).

A number of terpolymers derived from phenol derivatives have been studied and reported along with their chelating ionexchange properties. For example, (Karunakaran, and Burkanudeen, 2002) have synthesized terpolymer from onitrophenol-thiourea- formaldehyde and $\mathrm{Fe}^{2+}, \mathrm{Co}^{2+}, \mathrm{Ni}^{2+}$ and $\mathrm{Cu}^{2+}$ were used for chelation. Das, (2000) has derived copolymer from thiosemicarbazone derivatives of phenolic compound. Terpolymers of 8-hydroxy quinolineformaldehyde-resorcinol/catechol were reported by Shah et al., (2004) and Shah et al., (2003) and chromatographic column separation for various metal ions such as $\mathrm{Cu}^{2+} \mathrm{Ni}^{2+}, \mathrm{Zn}^{2+}, \mathrm{Pb}^{2+}$ and $\mathrm{Cd}^{2+}$ have carried out using the quinoline base resins. Rimawi et al., (2004) have studied the chelation behaviour of the phenolic-formaldehyde polymers, $\operatorname{poly}(2,4-$ dihydroxybenzoic acid-3,5-dimethylene), poly(2hydroxybenzoic acid-3,5- dimethylene) and poly(3hydroxybenzoic acid-4,6-dimethylene) towards the trivalent lanthanide metal ions such as $\mathrm{La}^{3+}, \mathrm{Nd}^{3+}, \mathrm{Sm}^{3+}, \mathrm{Gd}^{3+}$ and $\mathrm{Tb}^{3+}$ by a static batch equilibrium technique at $25^{\circ} \mathrm{C}$ as a function of contact time, $\mathrm{pH}$, and concentration. Polymer supported reagents (Beauvais, and Alexandratos, 1998) containing various ligands have been studied for their selective 
complexation towards various metal ions. Dabrowski et al.(2004) have efficiently removed trace impurities and toxic metals from industrial waste water by various ion exchangers. o-Nitro phenol and thiourea with para-formaldehyde copolymer was identified as an excellent cation exchanger for $\mathrm{Zn}^{2+}$ and $\mathrm{Co}^{2+}$ ions (Burkanudeen, and Karunakaran, 2002).

A chelating ion exchange terpolymer resin p-NPHXF was synthesized by the condensation of p-nitro phenol and hexamine using formaldehyde as a cross linking agent at 140 ${ }^{\circ} \mathrm{C}$ in a mole ratios of 2:1:4 in presence of glacial acetic acid as a catalyst. The resin was chracterized by FTIR and elemental analysis , and its ion exchange study was carried out with $\mathrm{Cd}^{2+}$ and $\mathrm{Pb}^{2+}$ ( Gaitry Copta, 2014).

Among a recent application in medicine to stop or inhibit a certain tumour growth, a terpolymer complex was synthesized via enzyme catalyzed copolymerization of lactone with dialkyle diester and amiondiol, and their hydrophobically adjusted by varying the lactone content and by selecting a lactone comonomer of specific ring size (Zhou, et al., 2012).

Azarudeen and Burkanudeen (2012) prepared a terpolymer drived from anthranilic acid -phenyl hydrazine - formaldehyde and used it as a ligand for a complexation to metal ions $\mathrm{Cu}^{2+}$, $\mathrm{Mn}^{2+}$, and $\mathrm{Zn}^{2+}$. The prepared ligand (terpolymer) and its metal complexes were intended to spectral characterization viz, FTIR, electronic, ESR, ${ }^{1} \mathrm{H}$ NMR for elucidation of the chemical structures.

Certain metal ions such as $\mathrm{Ni}^{2+}, \mathrm{Cu}^{2+}$, and $\mathrm{Cr}^{6+}$ present as a pollutants in industrial waste waters could be removed by a

TABLE

Moles Of Starting MATERials AND \% Yields For THe Synthesize OF SPFTERPOlymer Resins.

\begin{tabular}{|c|c|c|c|c|c|}
\hline \multirow{2}{*}{ Terpolymer } & \multicolumn{3}{|c|}{ Reactants (moles) } & Catalyst 2 M & Yield, \% \\
\cline { 2 - 4 } & Salicylic acid & Acryloamide & Furfural & \\
\hline SAF-1 & $\mathbf{0 . 0 1}$ & $\mathbf{0 . 0 1}$ & $\mathbf{0 . 0 2}$ & $\mathbf{1 0 0}$ & $\mathbf{8 5}$ \\
\hline SAF-2 & $\mathbf{0 . 0 2}$ & $\mathbf{0 . 0 2}$ & $\mathbf{0 . 0 4}$ & $\mathbf{1 0 0}$ & $\mathbf{8 6}$ \\
\hline SAF-3 & $\mathbf{0 . 0 3}$ & $\mathbf{0 . 0 3}$ & $\mathbf{0 . 0 6}$ & $\mathbf{1 0 0}$ & $\mathbf{9 1}$ \\
\hline SAF-4 & $\mathbf{0 . 0 4}$ & $\mathbf{0 . 0 4}$ & $\mathbf{0 . 0 8}$ & $\mathbf{1 0 0}$ & $\mathbf{9 2}$ \\
\hline
\end{tabular}

\section{B. Determination of metal uptake}

Metal uptake was determined in different $\mathrm{pH}$ media by using the prepared terpolymers according to the following procedure. Terpolymer sample $(25 \mathrm{mg}$ ) was suspended in 25 ml electrolyte solution of $\mathrm{NaNO}_{3}$ of known concentration. The $\mathrm{pH}$ of the suspension was adjusted to the required value by using suitable reagent of $0.1 \mathrm{~N} \mathrm{HCl}$ or $0.1 \mathrm{~N} \mathrm{NaOH}$. The suspension was stirred for a period of $24 \mathrm{~h}$ at $25^{\circ} \mathrm{C}$. To this suspension $2 \mathrm{ml}$ of $0.1 \mathrm{M}$ solution of the metal ion was added and the $\mathrm{pH}$ was adjusted to the required value. The mixture was again stirred at $25^{\circ} \mathrm{C}$ for $24 \mathrm{~h}$ and filtered. The solid was washed and the filtrate and washings were combined and the metal ion contents as well as their concentrations were determined by Atomic Absorption spectrophotometery for Cadmium, and Lead. While for Mercury, the procedure of Mudakavi (1984) modified by Al-Imarah et al., (2000) was used. The procedure for $\mathrm{Hg}^{2+}$ uptake was conducted in $\mathrm{NaCl}$ as an electrolyte, the results were nearly the same as those for $\mathrm{NaNO}_{3}$ electrolyte. polymerin microfilitration proccess and adjusted $\mathrm{pH}$ (Swaminathan et al., 2012).

In a recent study a noval chelating terpolymer resin has been prepared by terpolymerization of anthranilic acid , salysilic acid, and formaldehyde (ASF) in a molar ratios of $1: 1: 2$, and the prepared terpolymer were studied spectrophotometrically and thermogravimetricallyas well as the selectivity and binding capacity towards certain divalent metals (Azarudeen et al., 2010).

\section{EXPERIMENTAL}

\section{A. Polymer syntheses}

Starting materials Salicylic acid (0.01 M, 1.38g), Acryloamide $(0.01 \mathrm{M}, 0.71 \mathrm{~g})$ and Furfural $(0.02 \mathrm{M}, 1.92 \mathrm{ml})$ were mixed in a round bottom flask. $100 \mathrm{ml}$ of $2 \mathrm{M} \mathrm{HCl}$ was added slowly to the reaction mixture and the contents were refluxed at 100$120^{\circ} \mathrm{C}$ for $8-10$ hours on an oil bath with periodic shaking. After completion of the reaction, the mixture was poured in ice cold water, filtered and then washed with hot water to remove unreacted starting materials. Finally, the product was washed with alcohol and dried in vacuum. The yield of the terpolymer was found to be about $85-86 \%$. Other SAF terpolymers were synthesized following the same procedure with different stoicheometric starting materials $\mathrm{S}, \mathrm{A}$, and $\mathrm{F}$ as listed in table 1. 


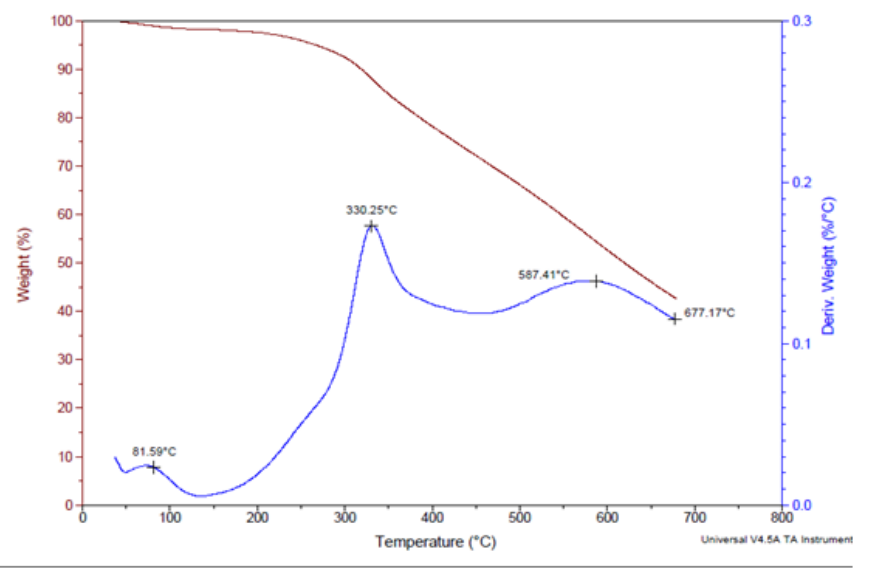

Fig. 2: A typical thermogravimetric analysis curve for SAF resin

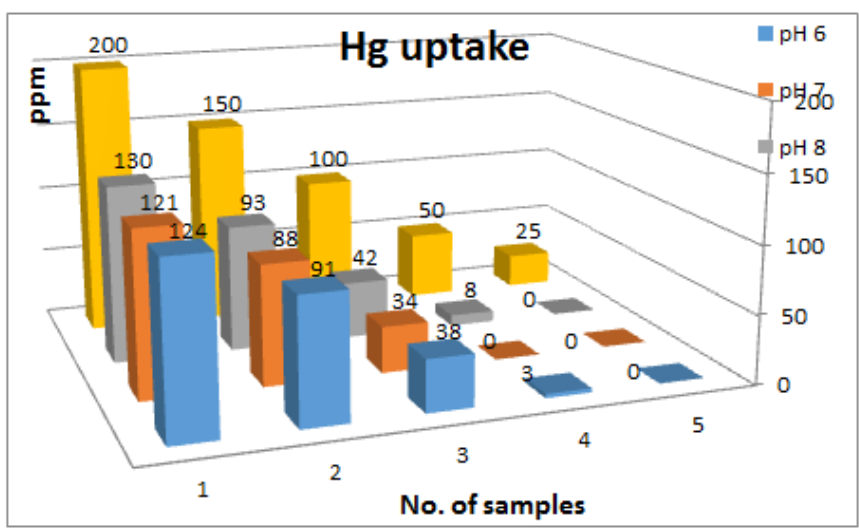

Fig. 3: Metal uptake of 25, 50, 100, 150, and $200 \mu \mathrm{g} / \mathrm{ml} \mathrm{Hg}^{2+}$ by SAF terpolymer at $\mathrm{pH}$ 's 6,7 , and 8 .

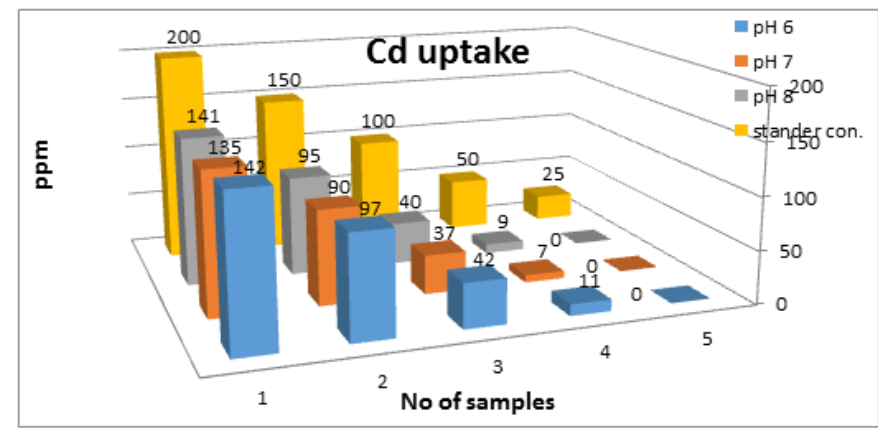

Fig. 4: Cd uptake of $25,50,100,150$, and $200 \mu \mathrm{g} / \mathrm{ml} \mathrm{Cd}^{2+}$ by SAF terpolymer at $\mathrm{pH}$ 's 6,7 , and 8 .

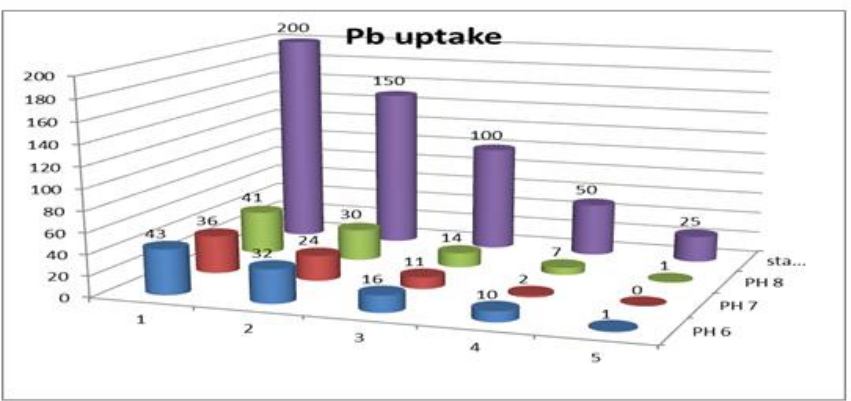

Fig. 4: $\mathrm{Pb}$ uptake of $25,50,100,150$, and $200 \mu \mathrm{g} / \mathrm{ml} \mathrm{Pb}^{2+}$ by SAF terpolymer at $\mathrm{pH}$ 's 6,7 , and 8 .

\section{DISCUSSION}

The reaction sequence of the synthesis of SAF terpolymer resin and expected structure are shown in Scheme 1.

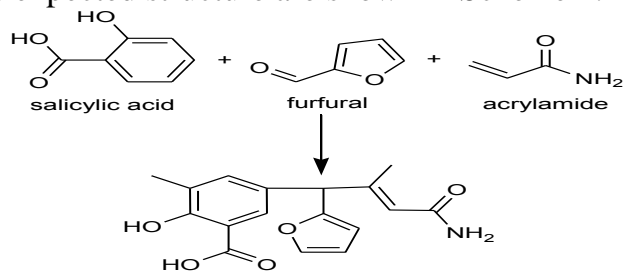

Scheme 1. Reaction between Salicylic acid ( S), Furfural (F), and acrylamide (A) and expected structure for the synthesized SAF's as concentration

According to table 1, the stochiometric ratios of monomers of $\mathrm{S}, \mathrm{A}$, and $\mathrm{F}$ were the same leading to increase percent yeild as concentrations of starting materiale were increased (Khwedem, 2013).

The important IR bands which appeared in the recorded FTIR spectrum of the SAF terpolymer resin along with their assignments are tabulated in Table 2. The spectrum shows a broad band at $3325.28 \mathrm{~cm}^{-1}$ due to the $(\mathrm{O}-\mathrm{H})$ stretching vibration of $\mathrm{Ar}-\mathrm{OH}$ involved in the intramolecular hydrogen bonding with $\mathrm{Ar}-\mathrm{COOH}$. The strong band appeared at 1288.45 $\mathrm{cm}^{-1}$ is due to (C-N) stretching vibration of Ar-NH2 (Shah et al., 2008). The strong band at $1620.21 \mathrm{~cm}^{-1}$ may be assigned to $(\mathrm{C}=\mathrm{O})$ stretching vibration of the carboxyl group present in the resin molecule (Shah et al.,2006). The NH-stretching vibration of amino group seems to be merged with a broad band of $-\mathrm{OH}$ group of - $\mathrm{COOH}$ groups. The tetra-substitution in the benzene ring is established by the presence of the medium bands at 1016.49 and $790.81 \mathrm{~cm}^{-1}$ which are attributed to $(\mathrm{C}-\mathrm{H})$ bending vibration(Raj et al., 2010). The weak band at 2926.01 $\mathrm{cm}^{-1}$ is due to the $(\mathrm{C}-\mathrm{H})$ stretching vibration of methylene group ( Shah et al., 2008).

TABLE II

FTIR SPECTRAL DATA FOR SAF TERPOLYMER.

\begin{tabular}{|c|c|c|}
\hline \multirow{2}{*}{ Vibrational mode } & \multicolumn{2}{|c|}{ Wave number $\left(\mathrm{cm}^{-1}\right)$} \\
\cline { 2 - 3 } Cobserved \\
\hline -OH of Ar-OH group involved intramolecular hydrogen bonding with Ar- \\
COH & $3500-3200$ & 3325.28 \\
\hline Methylene(-CH2) stretching & $3000-2850$ & 2926.01 \\
\hline$>$ C=O Stretching (carboxylic ketone) & $1690-1620$ & 1620.21 \\
\hline $1,2,3,5-$ Substituted benzene ring & $1200-800$ & $1016.49 \& 790.81$ \\
\hline (C-N) Stretching of Ar-NH2 & $1200-1300$ & 1288.45 \\
\hline Aromatic ring stretching (C-H) & $2700-3000$ & 2900 \\
\hline
\end{tabular}


The thermogravimetric analysis is an effective tool to assess the thermal stability of the terpolymer resin. The thermogram of the terpolymer resin SAF which is shown in Figure 2 from which the thermogravimetric data are extracted and tabulated in Table 3, revealed that the SAF resin exhibits three stages of degradation pattern. The first degradation stage begins at $81.59^{\circ} \mathrm{C}$ and it extends to $330.25^{\circ} \mathrm{C}$ with the weight loss of $20 \%$ which corresponds to the loss of carboxylic group attached to the aromatic ring as $\mathrm{CO}_{2}$ [ Azarudeen et al., 2009. ]. The second degradation takes place from $330.25^{\circ} \mathrm{C}$ and ends at $587.41^{\circ} \mathrm{C}$ with the weight loss of $35 \%$ which may be due to the elimination of side chain attached to the aromatic ring. Finally the third degradation stage starts at $587.41^{\circ} \mathrm{C}$ and the complete degradation takes place at $677.17^{\circ} \mathrm{C}$. After $700{ }^{\circ} \mathrm{C}$ almost the entire resin was lost and decomposition could be taken place (karunakaran and Magesh, 2011).

TABLE III

THERMOGRAVIMETRIC DEGRADATION OF TERPOLYMER RESIN SAF

\begin{tabular}{|c|c|}
\hline Temperature, ${ }^{\circ} \mathrm{C}$ & $\begin{array}{c}\text { Weight loss of resin } \\
\%\end{array}$ \\
\hline 100 & - \\
\hline 200 & 5 \\
\hline 300 & 20 \\
\hline 400 & 25 \\
\hline 500 & 30 \\
\hline 60 & 40 \\
\hline 700 & 60 \\
\hline 800 & 100 \\
\hline
\end{tabular}

The chelating ion-exchange property of the ASF terpolymer resin was adopted for uptaking $\mathrm{Hg}^{2+}, \mathrm{Cd}^{2+}$,and $\mathrm{Pb}^{2+}$ ions in a certain concentration of $\mathrm{NaNO}_{3}$ electrolyte and at a $\mathrm{pH}$ range of 5-8 as well as a concentration range for the metal ions in the range $25,50,100,150$, and $200 \mu \mathrm{g} / \mathrm{ml}$. The results for the removal of divalent ions $\mathrm{Cd}^{2+}, \mathrm{Hg}^{2+}$, and $\mathrm{Pb}^{2+}$ which are shown in figures 3,4 , and 5 indicate that the amount of metal ions uptake for a given amount of terpolymer resin $\mathrm{SAF}$ depands on the nature of the divalent ion and the $\mathrm{pH}$ of the medium.

Sodium nitrate was preferred as an electrolyte for uptake of divalent ions $\mathrm{Cd}^{2+}, \mathrm{Hg}^{2+}$, and $\mathrm{Pb}^{2+}$ by terpolymer resin $\mathrm{SAF}$ due to the formation of weak chelates between the nitrate anion and metal ions ( Ahmed et al., 2010). Moreover, the upon the metand $\mathrm{Pb}^{2+}$ could be due to the presence of amino and hydroxyl groups in the structure of the resin ( Shah et al., 2008, Singru et al., 2008).

The amount of $\mathrm{Pb} 2+$ ions uptake by the SAF terpolymer resin is higher than that for the ions $\mathrm{Hg}^{2+}$, and $\mathrm{Cd}^{2+}$, this may be due to the relative weak chelation of $\mathrm{Pb} 2+$ ions with the anion $\mathrm{NO}_{3}$ of the used $\mathrm{NaNO}_{3}$ electrolyte compared to that of the $\mathrm{Cd}^{2+}$, and $\mathrm{Hg}^{2+}$ ions (Azarudeen, et al., 2008).

The uptake of metal ions by terpolymer resin depend upon the distribtion of these metals between the polymer phase and the aqueous phase. Within this study the $\mathrm{pH}$ range used were 5-8, higher $\mathrm{pH}$ will lead to hydrolysis of metal ions and the formation of metal hydroxide interferes with the ion exchange process (Azarudeen, et al., 2008). For the terpolymer resin $\mathrm{SAF}$, the $\mathrm{pH}$ showed a great effect upon the uptake of the metal ions $\mathrm{Hg}^{2+}, \mathrm{Cd}^{2+}$,and $\mathrm{Pb}^{2+}$. The results revealed that the optimum $\mathrm{pH}$ value was 7 in which the uptake was completely leading to zero concentrations of the metal ions and the order of the removal of the toxic metal ions was $\mathrm{Pb}^{2+}>\mathrm{Hg}^{2+}>\mathrm{Cd}^{2+}$.

\section{CONCLUSION}

The distribution of metal ions between terpolymer phase and the aqueous phase depend upon the metal ion, terpolymer resin, and the $\mathrm{pH}$ of the solution. All of these electrolyte parameters have a great effect upon the ion exchange resins, the removal or uptake of the toxic trace element ions by a certain terpolymer ion exchange resins. According to this study, the prepared terpolymer SAF could be used to remove toxic elements $\mathrm{Cd}^{2+}, \mathrm{Hg}^{2+}$, and $\mathrm{Pb}^{2+}$...etc which may exist in the industrial waste water before water recycling or discharging directly into surface water. For even more effective removal of toxic ion pollutants, this procedure could be adopted together with any other technique such as RO, Ultrafiltration, membrane separation ... etc. Furthermore, the results of this study revealed that the most effective composition for the removal of toxic ions is the following: $\mathrm{SAF}$ terpolymer resin, at $\mathrm{pH} 7$ and $\mathrm{NaNO}_{3}$ as an electrolyte.

\section{REFERENCES}

[1] Ahmed, M. A. R., Azarudeen, A. M. A, R.,.Karunakaran, R. S., and Burkanudeen, M.A.R.(2010). Synthesis, characterization, metal ion binding capacities and applications of a terpolymer resin of anthranilik acid/salycilic acid/formaldehyde. Iranian Polym. J. ,19(8):635 - 646

[2] Alchin, D. (2004). Ion exchange resins. Service Chemist, Drew New Zealand. pp 7.

[3] Al-Imarah Faris J. M., Abdul-Hameed M. Jawad and Seta A. Keurk (2009). Levels of Mercury in Ground water at Basrah, South of Iraq. Uruk for Sci. Res., 2: 97-103.

[4] Azarudeen, R.S., Riswan Ahamed, M.A., Jeyakumar, D., Burkanudeen, A. R., (2009). An eco-friendly synthesis of a terpolymer resin: characterization and chela- tion ion-exchange property, Iran Polym J, 18:821-832.

[5] Azarudeen, R. S., and Burkanudeen, A. R. (2010). Synthesis, Spectral, morphology, thermal degradation kinetics and antibactrial studies of terpolymer metal complexes. J. Inor. Organom. Polym. and Materials, 22(4):791-806.

https://doi.org/10.1007/s10904-011-9631-2

[6] Azarudeen, R. S., and Burkanudeen A. R., (2012). Synthesis, spectral, morphology, thermal degradation kinetics and antibacterial studies of terpolymer metal complexes. J. Inorg. and Organomet. Poly. and Mat.,22(4):791-806.

[7] Beauvais, R.A. and Alexandratos, S.D., (1998) Polymer supported reagents for the selective complexation of metal ions: An overview, React. Funct. Polym., 36:113-123.

https://doi.org/10.1016/S1381-5148(98)00016-9

[8] Dabrowski A., Hubicki Z., Podkoscielny P. and Robens E., (2004) Selective removal of the heavy metal ions from waste waters and industrial wastewaters by ion-exchange method. Chemosphere, 56:91106

https://doi.org/10.1016/j.chemosphere.2004.03.006

[9] Das, S.C., (2000) Ion exchange studies of resin copolymer derived from aromatic hydroxyl compounds. J. Indian Chem. Soc., 77:66-69.

[10] Gaitry Chopra, P. K. P. (2014). Synthesis , characterization and metal ion binding capacities of resin derived from p-Nitro phenol, hexamine, and formaldehyde. Int. Interdispl. Res. J. IV(III):154-159.

[11] Helfferich F., (1962). Ion Exchange Resins, Mc-Grow Hill:New York).

[12] Karunakaran, M. and Burkanudeen, A., (2002) Chelation ion exchange properties of orthonitro phenolthiourea-paraformaldehyde terpolymer, Orient. J. Chem., 18:65-68.

[13] Karunakaran, M. and Magesh, C. (2011). Thermal and ion exchange studies on chelating terpolymer resins derived from o-cresol, urea, and 
formaldehyde. Arabian J. Dhem., 4(3):339-348. https://doi.org/10.1016/j.arabjc.2010.06.057

[14] Khwedem, A. A. A. (2013). Preparation of Polymeric Resins and their Applications as Selective Chelating Complexation to Some Heavy Metals. M.Sc. Thesis, Al-Qadisyia University pp: 100

[15] Mudakavi, J. R. (1984). Spectrophotometric determination of trace amount of mercury with phenanthroline and eosin. Analyst, 109:15771599. https://doi.org/10.1039/an9840901577

[16] Raj JA, Vedhi C, Burkanudeen A, Arumugam P, Manisankar P(2010). Synthesis and characterization of novel nano-size polyreactive yellow 107. Ionics, 16, 171-175 https://doi.org/10.1007/s11581-009-0328-2

[17] Rimawi, F.A., Ahmad, A., Khalili, F.I. and Mubarak M., (2004) Chelating properties of some phenolic formaldehyde polymers towards some lanthanide ions, Solvent Extr. Ion Exch., 22:721-735. https://doi.org/10.1081/SEI-120039645

[18] Sayed Abuthahir, S. S., Shanthy, P. V., Vijaya,N., Joseph Rathish, R., Santhana Prabha, S., Jamal Abdul Nasser, A., and Rajenderan, S.,(2014). Recent trends in terpolymer preparation and characterization as overview. Int.J. Nano Corr. Sci. Enj.,1(1):63-73.

[19] Shah, B.A., Shah, A.V. and Bhandari, B.N., (2003) Selective elution of metal ions on a new chelating ion exchange resin derived from substituted 8- hydroxyquinoline. Asian J. Chem., 15, pp. 117-125.

[20] Shah, B.A., Shah, A.V. and Bhandari B.N., (2004) Recovery of transition metal ions from binary mixtures by ion exchange column chromatography using synthesized chelating ion resin derived from mcresol. Asian J. Chem., 16:1801-1810.

[21] Shah,B. A., Shah, A.V., Shah, P.M., (2006). Synthesis, characterization, and analytical applications of o-substituted benzoic acid chelating resin. Iran Polym J, 15:809-819.

[22] Shah, B. A., Shah, A. V. and Bhatt, R. R. (2007). Studies of Chelation Ion-exchange Properties of Copolymer Resin Derived from Salicylic Acid and its Analytical Applications. Iranian Polymer Journal. 16 (3): 173-184

[23] Shah P. M., Shah A.V., and Shah B.A. (2008). Metal ions uptake by chelating resin derived from o-substituted benzoic acid and its synthesis, characterization and properties. Macromol Symp, 274:81- 90. https://doi.org/10.1002/masy.200851412

[24] Shah, B. A., Shah, A. V., Shah, P. M. (2010). Removal, Separation and Enrichment of Trace Metals in Aqueous Solutions Play an Important Role for the Analysis of Wastewaters, Industrial and Geological Samples, as well as for Environmental Remediation. Iran. J. Chem. Eng. 29( 2):49-58

[25] Singru, R. N., Zade, A. B., and Gurnule, W. B. (2008). Synthesis, Characterization, and thermal degradation studies of copolymer resin derived from p-cresol, melamine, and formaldehyde. J. Appl. Polmer, Sci., 109:859-868.

[26] Swaminathan, E., Nagappan, S., Rajangam, P., and Dharmallingam, .,(2012). Prog. Nanotech. Nanomat., 11(1):100-106

[27] Tarase, M. V., Gurnule, W. B. and Zade, A. B. (2009). Ion Exchange Properties of a Terpolymer Resin Derived from 2, 4Dihydroxybenzaldehyde, Oxamide and Formaldehyde. E-Journal of Chemistry. 6(3):639-650 https://doi.org/10.1155/2009/164129

[28] Zhou, J., Liu, Cheng, C, J., Patal, T. R., Weller, C. E., Piepmeir, J. M., Jiang, Z., and Saltzman, W. M.,(2012). Biodegradable poly (amion-coester) terpolymer for targeted gene delivery. Nature Material,11:82-90. https://doi.org/10.1038/nmat3187 